\title{
ASSESSMENT OF FIRE SEVERITY AND POST-FIRE REGENERATION BASED ON TOPOGRAPHICAL FEATURES USING MULTITEMPORAL LANDSAT IMAGERY: A CASE STUDY in MERSIN, TURKEY
}

\author{
H.Tonbul $^{\text {a* }}$, T. Kavzoglu ${ }^{\text {a }}$, S. Kaya ${ }^{\text {b }}$ \\ ${ }^{a}$ Dept. of Geodetic and Photogrammetric Engineering, Gebze Technical University, 41400 Gebze Kocaeli, Turkey \\ (kavzoglu, htonbul)@gtu.edu.tr \\ ${ }^{\mathrm{b}}$ Istanbul Technical University, Dept. Of Geomatic Engineering, 80626 Maslak Istanbul, Turkey, 34469, Maslak, Istanbul \\ (kayasina@itu.edu.tr)
}

Commission VIII, WG VIII/7

KEY WORDS: dNBR, Fire Severity, Landsat ETM+, NDVI, SAVI, Vegetation Regeneration, Wildfire

\begin{abstract}
:
Satellite based remote sensing technologies and Geographical Information Systems (GIS) present operable and cost-effective solutions for mapping fires and observing post-fire regeneration. Mersin-Gülnar wildfire, which occurred in August 2008 in Turkey, selected as study site. The fire was devastating and continued 55 days. According to Turkish General Directorate of Forestry reports, it caused two deaths and left hundreds of people homeless. The aim of this study is to determine the fire severity and monitor vegetation recovery with using multitemporal spectral indices together with topographical factors. Pre-fire and post-fire Landsat ETM+ images were obtained to assess the related fire severity with using the widely-used differenced Normalized Burn Ratio (dNBR) algorithm. Also, the Normalized Vegetation Index (NDVI) and Soil Adjusted Vegetation Index (SAVI) were used to determine vegetation regeneration dynamics for a period of six consecutive years. In addition, aspect image derived from Aster Global Digital Elevation Model (GDEM) were used to determine vegetation regeneration regime of the study area. Results showed that 5388 ha of area burned with moderate to high severity damage. As expected, NDVI and SAVI values distinctly declined postfire and then began to increase in the coming years. Mean NDVI value of burned area changed from 0.48 to 0.17 due to wildfire, whilst mean SAVI value changed from 0.61 to 0.26 . Re-growth rates calculated for NDVI and SAVI $57 \%$ and $63 \%$ respectively, six years after the fire. Moreover, NDVI and SAVI were estimated six consecutive year period by taking into consideration east, south, north and west facing slopes. Analysis showed that north-facing and east-facing slopes have higher regeneration rates in compared to other aspects. This study serves as a window to an understanding of the process of fire severity and vegetation regeneration that is vital in wildfire management systems.
\end{abstract}

\section{INTRODUCTION}

Forests covering around $30 \%$ of Earth's surface provide vital organic infrastructure for ecosystem and environmental balance. They also contribute to genetic diversification and climate regulation. It is a well-known fact that global forest cover has decreased sharply during the last two decades and correspondingly deforestation and forest degradation increase in anthropogenic emissions of greenhouse gases have increased and led to climate change. Wildfires can be named as an important reason for the degradation of forests. They are uncontrolled fires that take places generally in countryside or wilderness area. Wildfires cause serious physical, chemical and biological damages on ecosystem and modify spectral and spatial characteristics of nature.

Being a major disaster all over the world, wildfires lead to essential modifications on natural ecosystem dynamics. Fires spread out greenhouse gas emissions and affect forest areas severely (Chuvieco, 2008). In the Mediterranean region, wildfires constitute a major problem due to meteorological conditions, topographical factors and agricultural abandonments (Amraoui et al., 2013; Kaya et al., 2014; Viedma, 2008). In the last five-year, average annual number of forest fires has been about 2100 destroying 6400 ha forested land in Turkey according to the statistics of Turkish General Directorate of Forestry (OGM, 2014). It is obvious that comprehensive assessment of post-fire vegetation recovery is crucial in management of forested lands in Turkey.
Satellite imagery present a reasonable way to determine burn severity and monitor vegetation recovery by detecting the variation in reflectance by virtue of fire effects on vegetation (Chen et al., 2011). Among numerous satellite sensors, Landsat is a free of charge multispectral multi-high resolution sensor providing synoptic coverage of Earth. Therefore, this satellite comprehensively has been used for mapping burned areas and post-fire vegetation studies (Ireland and Petropoulos, 2015; Petropoulos et al., 2014; Wittenberg et al., 2007). Landsat images have 30-meter spatial resolution and spectral 7 bands resolutions that is satisfactory for detection of forest fire change distributions and observing post-fire vegetation regeneration events (Masek et al., 2008; Schroeder et al., 2007).

The use of spectral vegetation indices is very common in forest management studies. It is commonly agreed that most effective index in the literature for burn severity is the Normalized Burn Ratio (NBR), computed as the difference between near-infrared (NIR) and short-wave infrared (SWIR) reflectance divided by their sum (Key and Benson, 2005). Another most widely used index is the NDVI, which is indicator of vegetation greenness, measuring vegetation type and amount on land surfaces. It has been utilized in many studies to observe post-fire vegetation dynamics in Mediterranean region (e.g. Mitri and Gitas, 2010; Petropoulos et al., 2014; Veraverbeke et al., 2010). In addition, SAVI has been used as an alternative index to monitor post-fire dynamics which is operable to discern between areas with bare soil and vegetation.

Various studies have pointed out that post-fire growth is generally affected by topographical features (Fox et al., 2008; 
Ireland and Petropoulos, 2015; Wittenberg et al., 2007). In this context, this issue has been investigated with topography and aspect which related to post-fire regrowth (Ireland and Petropoulos, 2015; Petropoulos et al., 2014).

The objective of this study is twofold: (1) determining the total burn severity of the Mersin-Gülnar wildfire in Turkey by using remote sensing based spectral indices, and (2) assessing postfire vegetation dynamics using multitemporal analysis of Landsat ETM+ images and GIS techniques. In this investigation, burn severity and vegetation recovery were assessed by using NDVI, NBR and SAVI indices. Moreover, fire occurrences were analyzed in terms of topographical features of the study area.

\section{SITE DESCRIPTION}

The study was conducted at the nearly Gülnar - Bücükeceli region (Figure 1), located in the western part of Mersin
Province, Turkey. It is a hilly region with elevations ranging from 156 to $830 \mathrm{~m}$ above the sea level, while the slope angles reach to $88^{\circ}$. Calabrian pine is the dominant tree species at the region and other types of Mediterranean vegetation, (e.g. maquis). The climate is dry-summer subtropical, average summer temperature is $27.2^{\circ} \mathrm{C}$, average summer insolation time is 10.1 hour and average rainfall is $702 \mathrm{~mm}$.

In the summer of 2008, Turkey encountered one of the largest wildfires in its recent history. The fire began 07.07.2008 and continued 60 days. It intensified by fierce winds, destroyed nearly 5000 ha of forest, forcing the evacuation of thousands from the villages. This fire event was selected as a case study to explore the vegetation regeneration over a period of six years from 2008 to 2014 .

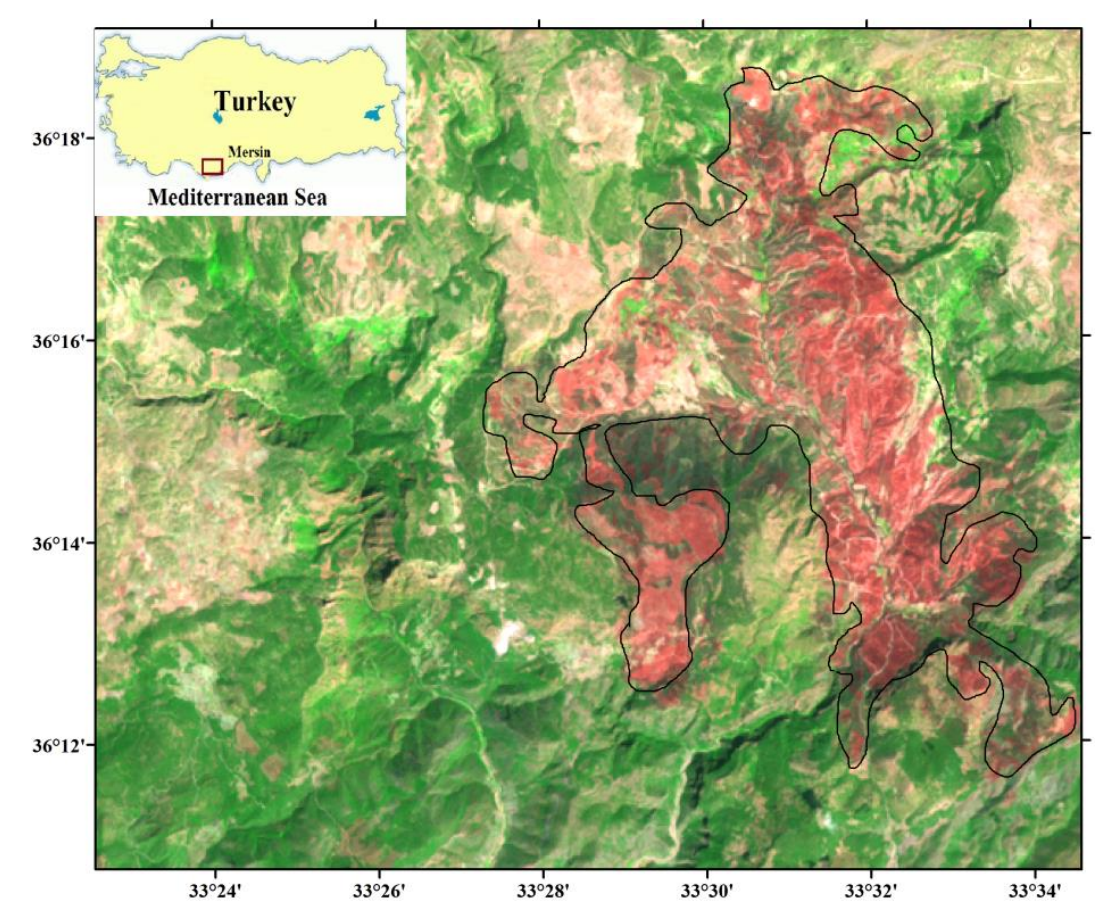

Figure 1. Location of study area

\section{DATASETS}

In this study, a total of four Landsat ETM+ images obtained from United States Geological Survey (USGS) Earth Explorer (http://earthexplorer.usgs.gov/) archives, was employed. In image selection, the seasonal occurrence of fire and the absence of clouds were taken in considerations. An ETM+ pre-fire image obtained on 7 April 2008 and three post-fire images were acquired on 14 September 2008, 19 June 2011 and 13 July 2014. All preprocessed (geometrically corrected and geometrically resampled) images were registered to UTM projection with WGS84 datum.

In addition, Advanced Spaceborne Thermal Emission and Reflection Radiometer (ASTER) Global Digital Elevation Model (GDEM) version 2 acquired from ASTER GDEM (http://gdem.ersdac.jspacesystems.or.jp/) to produce the digital elevation model which is used to extract topographical features of the study area. All analyses for determining burn severity and monitoring vegetation regeneration in this study were carried out using ERDAS Imagine (2013) and ArcGIS (v. 10.0) software packages.

\section{METHODS}

\subsection{Mapping Burn Severity}

One of the most widely used index for mapping burn severity, is normalized burn ratio (NBR), which combines the reflectance in the NIR and SWIR bands. NBR is a very sensitive index to emphasize burned areas and to determine severity of the burns.

$$
N B R=\frac{N I R-S W I R}{N I R+S W I R}
$$

Temporal difference between pre-fire and post-fire NBR to produce an index of burn severity, is expressed with an index called the Differenced Normalized Burn Ratio (dNBR). It is calculated from: 


$$
d N B R=N B R_{\text {pre }}-N B R_{\text {post }}
$$

In this study, pre-fire and post-fire NBR were calculated from ETM+ scenes, and then pre/post NBR ratios were differenced to calculate burn severity. A detailed overview of dNBR values (low, moderate, high) was generated from FIREMON program (USGS, 2004) shown in Table 1. Positive dNBR values express a decrease in vegetation while negative values express increased vegetation cover.

\begin{tabular}{|c|l|}
\hline dNBR & Burn Severity Class \\
\hline$<-0.25$ & Enhanced Regrowth, High \\
-0.25 to -0.10 & Enhanced Regrowth, Low \\
-0.10 to 0.10 & Unburned \\
0.10 to 0.27 & Low Severity \\
0.27 to 0.44 & Moderate-low Severity \\
0.44 to 0.66 & Moderate-high Severity \\
$>0.66$ & High Severity \\
\hline
\end{tabular}

Table 1. Burn Severity Level

\subsection{Post-Fire Vegetation Regeneration Assessment}

Vegetation regeneration assessment was carried out based on multitemporal analysis of NDVI and SAVI images. The NDVI calculation was based on Red (R) and NIR bands of image using the formula:

$$
N D V I=\frac{N I R-R}{N I R+R}
$$

NDVI values range from -1 to +1 , where low values $(0.1$ and below) correspond to absence of vegetation while high values ( 0.6 to 1$)$ indicate dense and healthy vegetation. Additionally, the SAVI was applied to estimate vegetation regrowth rates for further analysis; SAVI is calculated by following formula:

$$
S A V I=\frac{(1+L)(N I R-R)}{N I R+R+L}
$$

where $L$ is soil brightness correction factor and the value of $L$ varies by the amount of vegetation cover. Generally, $L=0.5$ works well in most situations and is the default value used in the vegetation literature. Similar to SAVI, ranges from -1 to +1 and lower values show sparse vegetation amount/cover.

The potential impact of aspect on post fire vegetation recovery dynamics was investigated. Aspect maps generated from previously obtained ASTER GDEM. Four topographic aspect slope entities were studied: North $(\mathrm{N})$ facing $\left(0^{\circ}-45^{\circ}\right.$, $\left.315^{\circ}-360^{\circ}\right)$, East $(\mathrm{E})$ facing $\left(45^{\circ}-135^{\circ}\right)$, South (S) facing $\left(135^{\circ}-225^{\circ}\right)$ and West $(\mathrm{W})$ facing $\left(225^{\circ}-315^{\circ}\right)$. Afterwards, NDVI and SAVI images were multiplied with the aspect image to extract vegetation information with regard to aspect of the terrain.

\section{RESULTS AND DISCUSSION}

Fire perimeter was delineated with using burned area boundaries. Burn severity map produced with the NBR and dNBR indices was classified into four major classes: low severity (LS), moderate-low severity (MLS), moderate-high severity (MHS) and high severity (HS) (Figure 2). The results obtained from the analysis of spatial distribution of burned area presents $28 \% \mathrm{HS}, 40 \% \mathrm{MHS}, 26 \%$ MLS and 6\% LS. It is apparent from the figure that Gülnar Wildfire could be categorized as a destructive fire, because more than $65 \%$ of the burned area was identified as moderate and high severity classes. The NDVI and SAVI values calculated for different dates and the regarding descriptive statistics for the burn scars are demonstrated in Table 2 and 3, respectively.

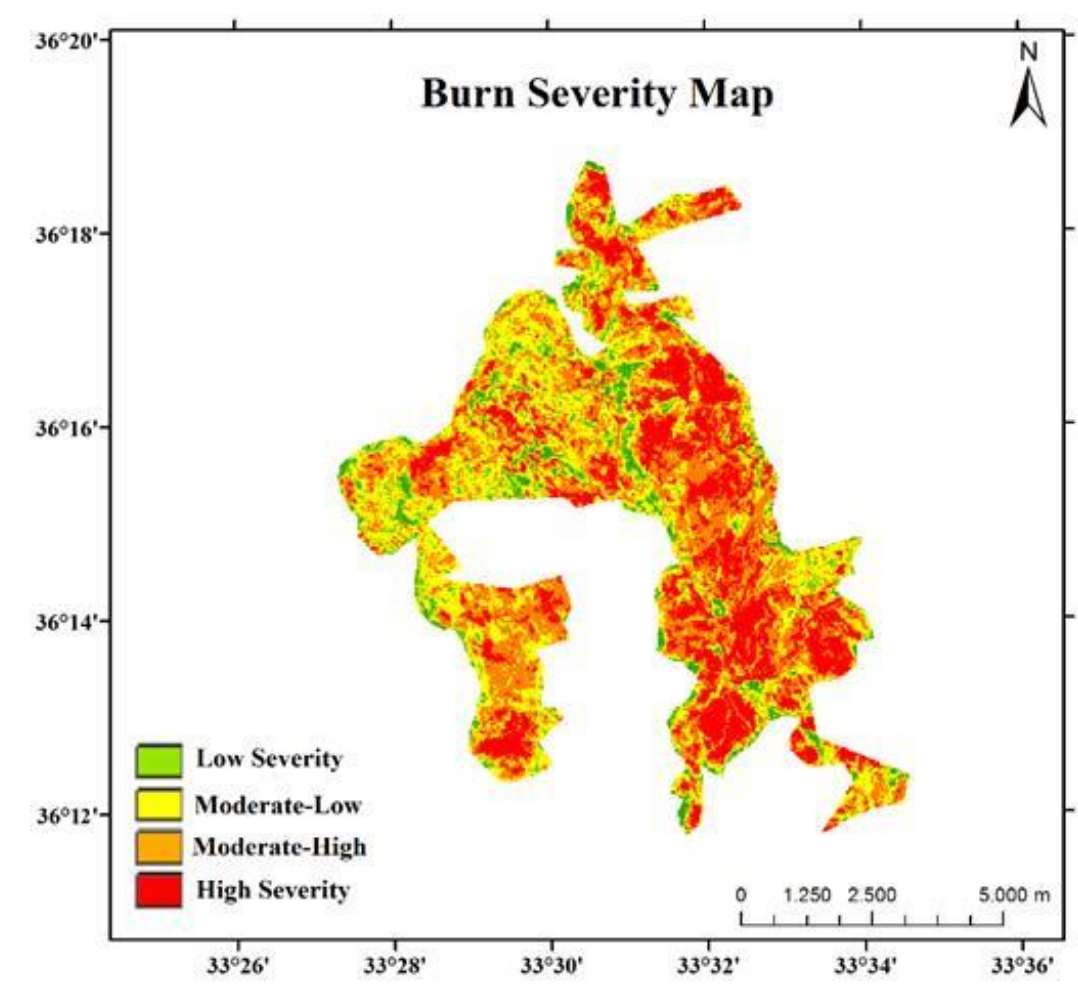

Figure 2. Burn Severity Classes 
In the first stage of analyses, amount of change in NDVI and SAVI values were analyzed for comparing the pre/post fire conditions. It is obvious that there are abrupt changes of NDVI-SAVI values on burned are when matching the pre/post fire conditions. As can be seen from Tables 2 and 3, mean NDVI for the area decreased from 0.48 to 0.17 while mean SAVI decreased from 0.61 to 0.26 after the fire. Six years after the fire, NDVI levels improved up to $57 \%$ of prefire levels, while SAVI values improved up to $63 \%$ of prefire levels. Undoubtedly, there is a moderate but stable raise in the mean NDVI and SAVI within the affected areas. This fact explains that vegetation recovery dynamics following a forest fire event take a long time.

The relationship between aspect and vegetation regeneration were also investigated using the ASTER GDEM data of the region. NDVI and SAVI values of each image were divided into 10 and 15 classes respectively and reclassified related to amount of photosynthetically active vegetation within each pixel. The results obtained from the preliminary analysis of healthy vegetation pixels of NDVI (values above 0.3 ) and SAVI (values above 0.4) calculated for determining spatial extension of vegetation regeneration.

\begin{tabular}{|c|c|c|c|c|}
\hline Image Date & $\begin{array}{c}\text { Min. } \\
\text { NDVI }\end{array}$ & $\begin{array}{c}\text { Max. } \\
\text { NDVI }\end{array}$ & $\begin{array}{c}\text { Mean } \\
\text { NDVI }\end{array}$ & $\begin{array}{c}\text { NDVI } \\
\text { Standard } \\
\text { Deviation }\end{array}$ \\
\hline $\begin{array}{c}\text { 7 April 2008 } \\
\text { (Pre-Fire) }\end{array}$ & -0.38 & 0.80 & 0.48 & 0.12 \\
\hline 14 Sept. 2008 & 0.03 & 0.59 & 0.17 & 0.06 \\
\hline 19 June 2011 & 0.07 & 0.76 & 0.31 & 0.09 \\
\hline 13 July 2014 & 0.09 & 0.73 & 0.34 & 0.08 \\
\hline
\end{tabular}

Table 2. Multitemporal NDVI statistics

Table 4 shows the number of healthy NDVI / SAVI pixels across the fire affected area and vegetation recovery ratio of consecutive six years separately for the north, south, west and east facing slope aspects. Analysis for main directions of the aspect (N, E, S, W) showed abrupt decline in NDVI / SAVI levels immediately after the fire, with a consistent tendency return pre-fire levels in the following date.

\begin{tabular}{|c|c|c|c|c|}
\hline Image Date & $\begin{array}{c}\text { Min. } \\
\text { SAVI }\end{array}$ & $\begin{array}{c}\text { Max. } \\
\text { SAVI }\end{array}$ & $\begin{array}{c}\text { Mean } \\
\text { SAVI }\end{array}$ & $\begin{array}{c}\text { SAVI } \\
\text { Standard } \\
\text { Deviation }\end{array}$ \\
\hline $\begin{array}{c}\text { 7 April 2008 } \\
\text { (Pre-Fire) }\end{array}$ & -0.57 & 0.94 & 0.61 & 0.19 \\
\hline 14 Sept. 2008 & 0.05 & 0.88 & 0.26 & 0.09 \\
\hline 19 June 2011 & 0.10 & 0.93 & 0.43 & 0.12 \\
\hline 13 July 2014 & 0.13 & 0.94 & 0.47 & 0.11 \\
\hline
\end{tabular}

Table 3. Multitemporal SAVI statistics

Also, a visual interpretation of the relationships between vegetation recovery and topography are presented in Figures 3 and 4, respectively. Comparing the two index results, it can be seen that stronger recovery dynamics appeared to occur in the East and North of the burn scar area. It is common with other studies and many authors finding that recovery was better on north facing slopes comparing to south facing slopes related to northern hemisphere dynamics (Fox et al., 2008; Wittenberg et al., 2007). Due to page limitations only NDVI-SAVI analyses for east and north facing terrain slopes are presented in Figures 3 and 4.

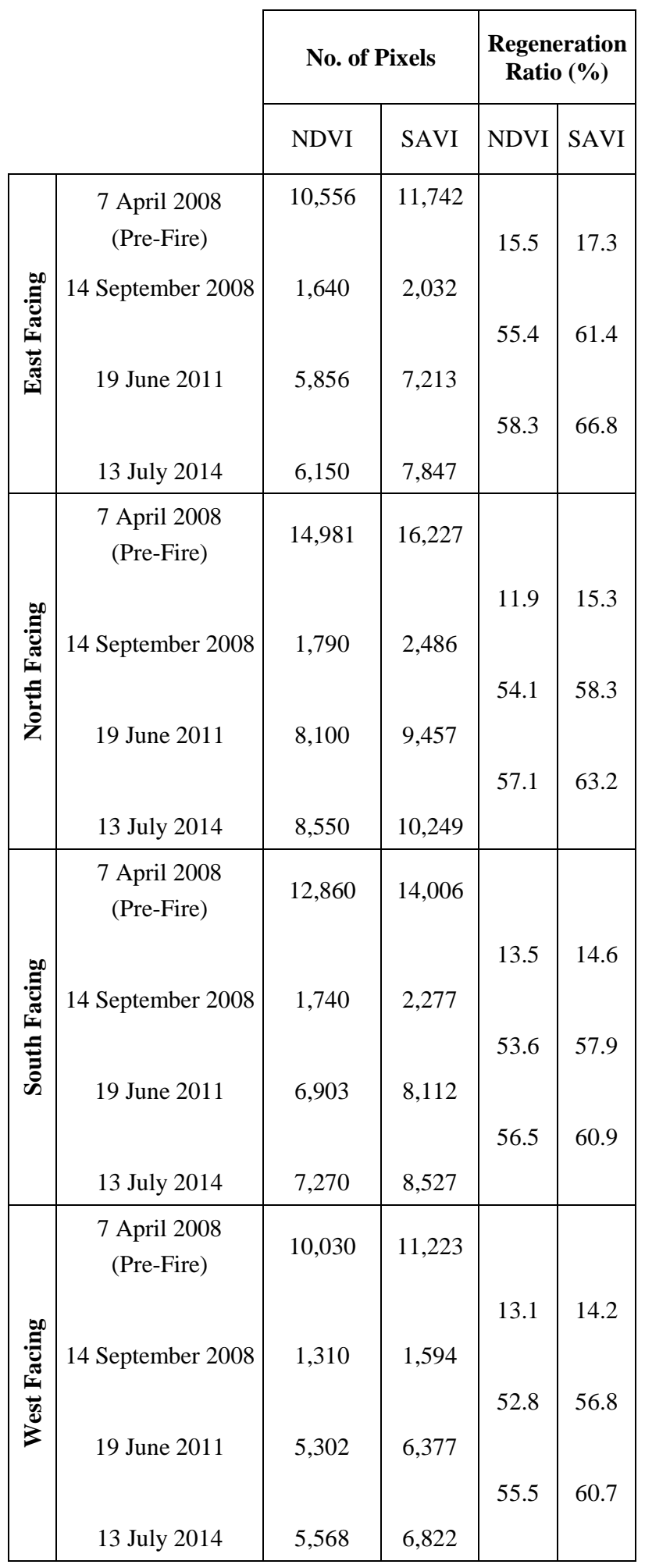

Table 4. NDVI and SAVI Regeneration Ratio in North, East, South and West directions 


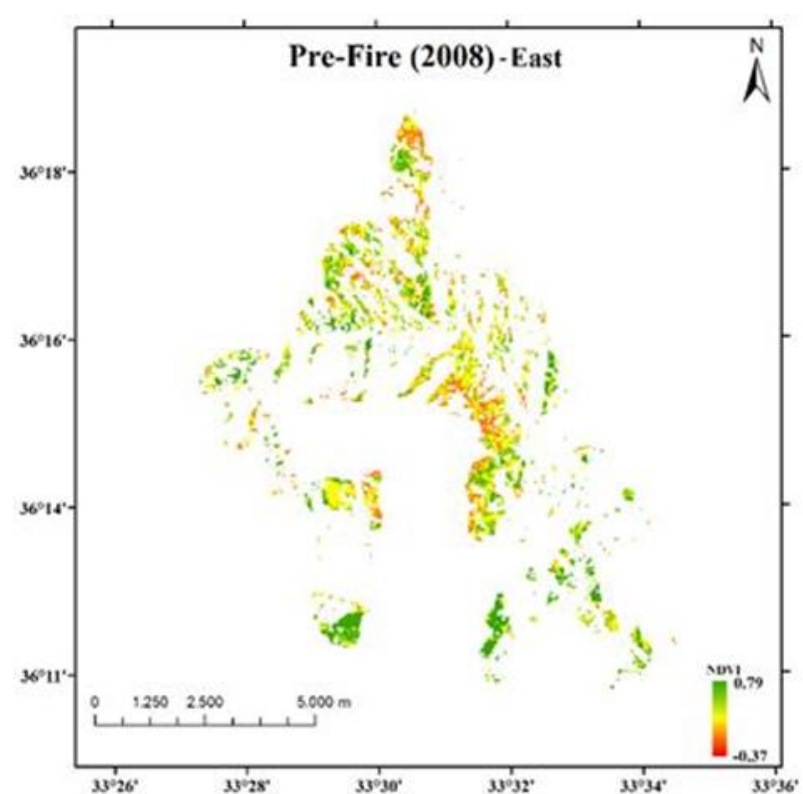

(a)

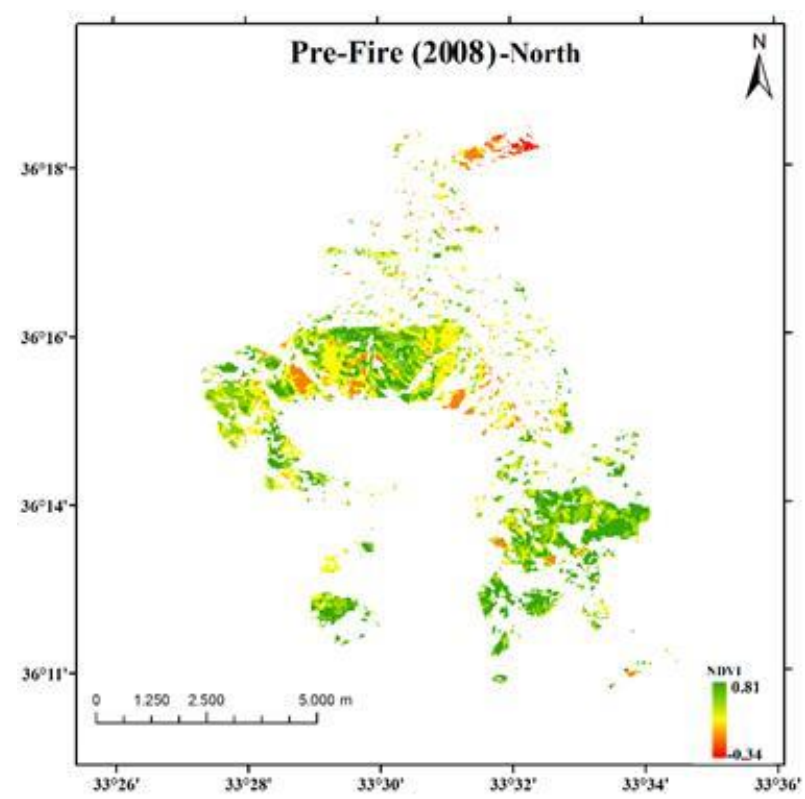

(c)

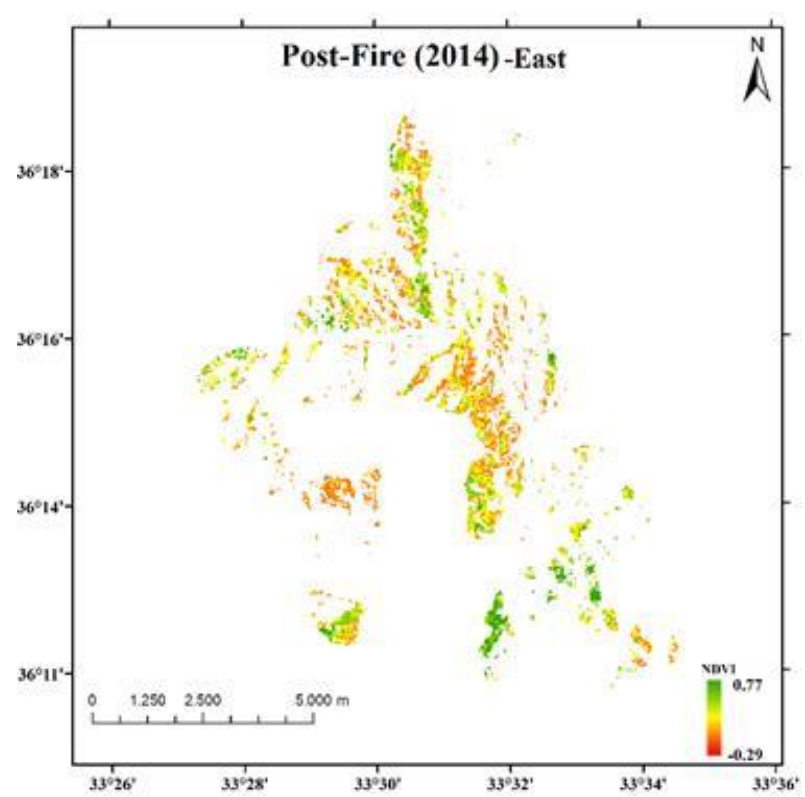

(b)

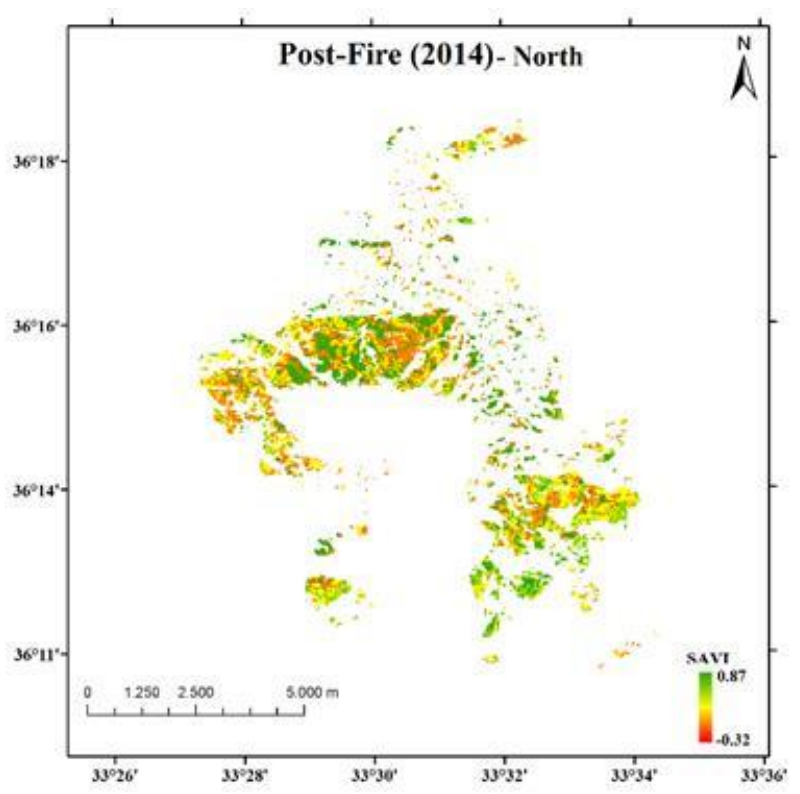

(d)

Figure 3. NDVI change maps for slope aspects (a) 2008 East, (b) 2014 East, (c) 2008 North, (d) 2014 North

Comparison may also be a preliminary of evaluation. Indeed, for instance, NDVI on east facing slopes increased from $15.5 \%$ to 55.4\% between September 2008 and June 2011 and then to $58.3 \%$, while SAVI on east facing slopes increased from $17.3 \%$ to $61.4 \%$ between September 2008 and June 2011 and then to $66.8 \%$ in the latter 6-year period. On north facing slopes, NDVI changed from $11.9 \%$ to $54.1 \%$ between September 2008 and June 2011 and then to $57.1 \%$, while SAVI changes from $15.3 \%$ to $\% 58.3$ between September 2008 and June 2011 and then to $63.2 \%$.
As shown in Table 4, on south- and west- facing slopes the increase appeared lower both NDVI and SAVI compared to east- and north- facing slopes. Furthermore, there are a number of similarities between the regrowth dynamics of NDVI and SAVI on aspect ways. The percentage increase in regenerated vegetation seems to be higher for SAVI in comparison to NDVI. 


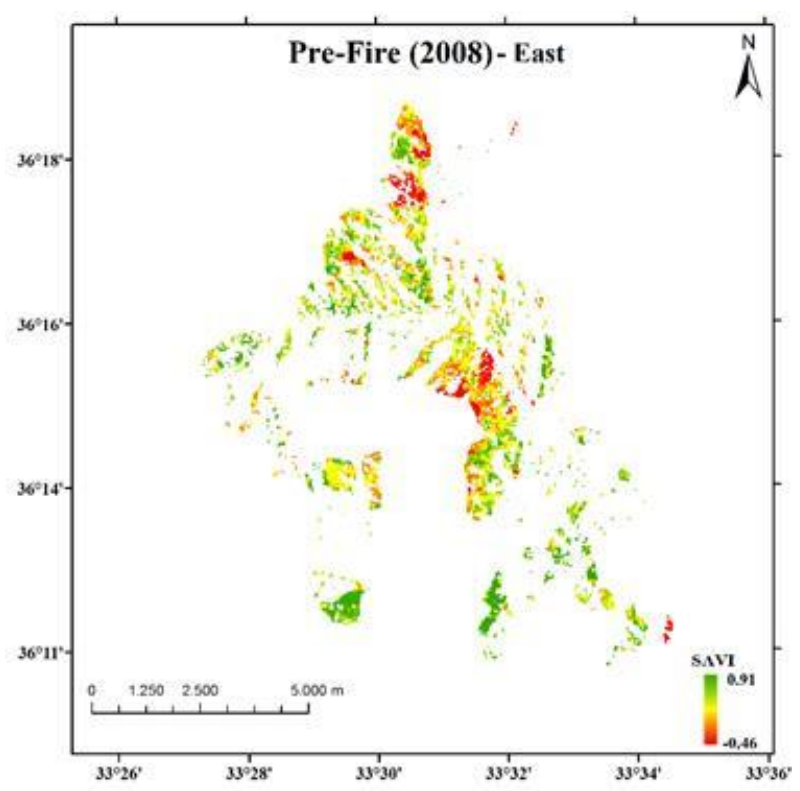

(a)

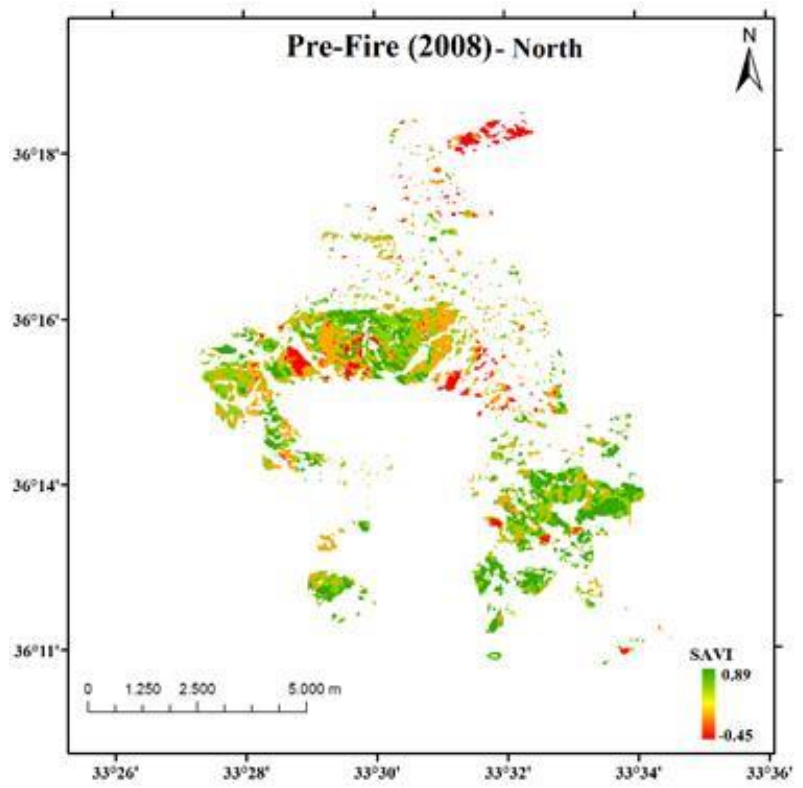

(c)

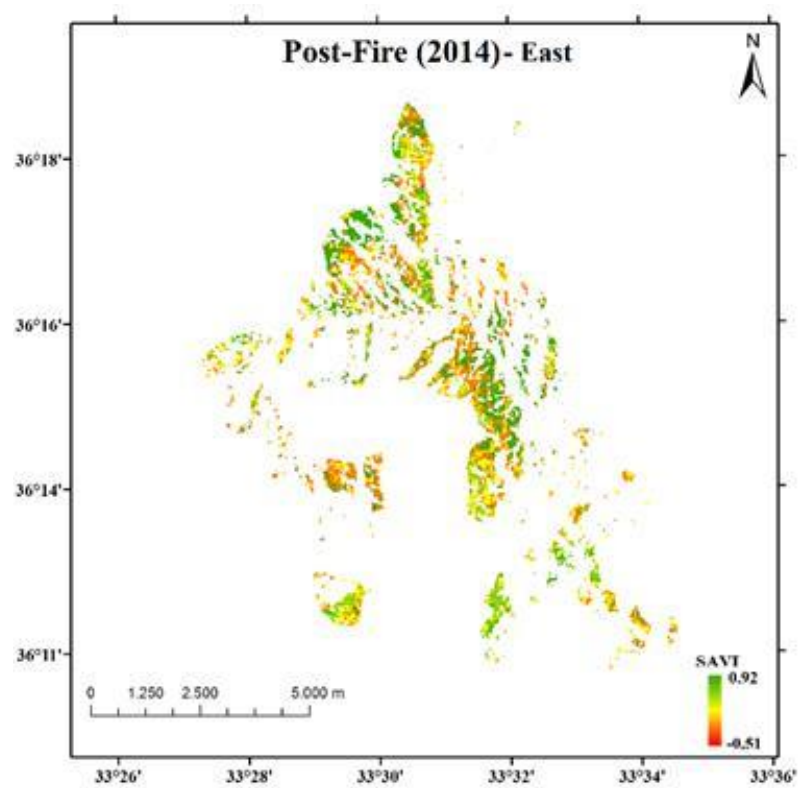

(b)

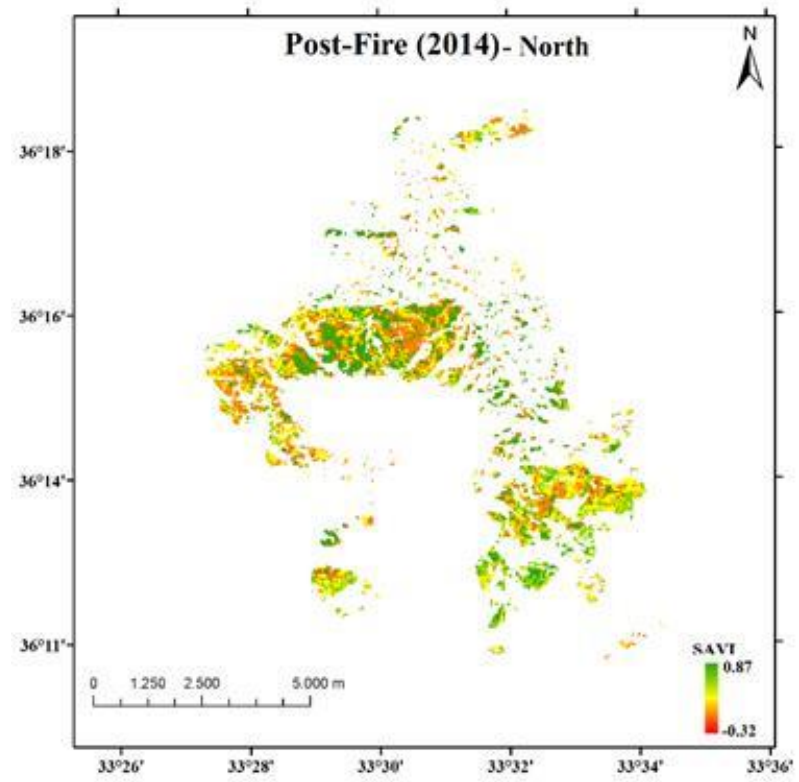

(d)

Figure 4. SAVI change maps for slope aspects (a) 2008 East, (b) 2014 East, (c) 2008 North, (d) 2014 North

\section{CONCLUSIONS}

The aim of this study was to map the fire scar and monitor post-fire vegetation restoration period of Mersin-Gülnar fire occurred in 2008, during a 6-year period using multitemporal Landsat ETM+ images. The time series allowed to analyze the damage and regrowth process of wildfire. In this context, spatio-temporal analysis between vegetation regeneration ratio, topographical dynamics and burn severity were also investigated. Detailed assessment of burn severity is costly and time consuming, the use of multi-temporal Landsat ETM+ images enable accurate mapping of burn severity and monitor long term vegetation cover trends related to aspect. An area of 5,388 ha was mapped as burned with moderate to high severity damage by using dNBR method. Analysis of vegetation regeneration in study area indicated that vegetation cover has recovered to around $60 \%$ of the pre-fire levels after 6 years according to NDVI-SAVI multitemporal validation. Post-fire SAVI spatial patterns showed a relatively rapid regeneration comparing with NDVI. It can be concluded that the use of SAVI to determine post-disturbance recovery could be an alternative to NDVI. Moreover, the analysis of regeneration with regard to topographical features revealed that north and east facing slope aspects displayed a 
slightly faster rate of recovery compared to west and south slope aspects. The current findings add a growing body of literature on vegetation recovery studies which can assist to better analyzing of fire management systems. Further work conducted to establish a better understand the relationship between topography and vegetation regrowth.

\section{ACKNOWLEDGEMENTS}

The authors would like to thank the USGS, NASA and Republic of Turkey General Directorate of Forestry for providing free access to their data used in this research.

\section{REFERENCES}

Amraoui, M., Liberato, M.L.R., Calado, T.J., DaCamara, C.C., Coelho, L.P., Trigo, R.M., Gouveia, C.M., 2013. Fire activity over Mediterranean Europe based on information from Meteosat-8. Forest Ecology and Management, 294, pp. $62-75$.

Chen, X., Vogelmann, J.E., Rollins, M., Ohlen, D., Key, C.H., Yang, L., Huang, C., Shi, H., 2011. Detecting post-fire burn severity and vegetation recovery using multitemporal remote sensing spectral indices and field-collected composite burn index data in a ponderosa pine forest. International Journal of Remote Sensing, 32, pp. 7905-7927.

Chuvieco, E., 2008. Satellite Observation of Biomass Burning Implications in Global Change Research, Earth Observation of Global Change: The Role of Satellite Remote Sensing in Monitoring the Global Environment, Elsevier, pp. 109-142.

Fox, D.M., Maselli, F., Carrega, P., 2008. Using SPOT images and field sampling to map burn severity and vegetation factors affecting post forest fire erosion risk. Catena, 75, pp.326-335.

Ireland, G., Petropoulos, G.P., 2015. Exploring the relationships between post-fire vegetation regeneration dynamics, topography and burn severity: A case study from the Montane Cordillera Ecozones of Western Canada. Applied Geography, 56, pp.232-248.

Kaya S., Kavzoglu T., Tonbul H., 2014. Detection of Burn Area and Severity with MODIS Satellite Images and Spatial Autocorrelation Techniques. AGU Fall Meeting, San Fransisco, CA, USA.

Key, C., N. Benson. 2005. "Landscape Assessment: Remote sensing of severity, the Normalized Burn Ratio; and ground measure of severity, the Composite Burn Index." In FIREMON: Fire Effects Monitoring and Inventory System, RMRS-GTR, Ogden, UT: USDA Forest Service, Rocky Mountain Research Station.

Masek, J.G., Huang, C., Wolfe, R., Cohen, W., Hall, F., Kutler, J., Nelson, P., 2008. North American forest disturbance mapped from a decadal Landsat record. Remote Sensing of Environment, 112, pp. 2914-2926.

Mitri, G.H., Gitas, I.Z., 2010. Mapping postfire vegetation recovery using EO-1 Hyperion imagery. IEEE Transactions on Geoscience and Remote Sensing, 48, pp. 1613-1618.
OGM 2014. "Orman Yangınları ile Mücadele Faaliyetleri Değerlendirme Raporu". T.C. Orman Bakanlığı, Ankara http://www.ogm.gov.tr/ekutuphane/FaaliyetRaporu/Orman\% 20Genel\%20M\%C3\%BCd\%C3\%BCr1\%C3\%BC\%C4\%9F\% C3\%BC\%202014\%20Y\%C4\%B11\%C4\%B1\%20Faaliyet\%2 0Raporu.pdf (15 Jan. 2016).

Petropoulos, G.P., Griffiths, H.M., Kalivas, D.P., 2014. Quantifying spatial and temporal vegetation recovery dynamics following a wildfire event in a Mediterranean landscape using EO data and GIS. Applied Geography, 50, pp. 120-131.

Schroeder, T.A., Cohen, W.B., Yang, Z., 2007. Patterns of forest regrowth following clearcutting in western Oregon as determined from a Landsat time-series. Forest Ecology and Management, 243, pp. 259-273.

USGS, 2014. FIREMON BR Cheat Sheet V.4 http://burnseverity.cr.usgs.gov/pdfs/LAv4_BR_CheatSheet. (11 Jan. 2016).

Veraverbeke, S., Verstraeten, W.W., Lhermitte, S., Goossens, R., 2010. Evaluating Landsat Thematic Mapper spectral indices for estimating burn severity of the 2007 Peloponnese wildfires in Greece. International Journal of Wildland Fire, 19 , pp. 558-569.

Viedma, O., 2008. The influence of topography and fire in controlling landscape composition and structure in Sierra de Gredos (Central Spain). Landscape Ecology, 23, pp.657-672.

Wittenberg, L., Malkinson, D., Beeri, O., Halutzy, A., Tesler, N., 2007. Spatial and temporal patterns of vegetation recovery following sequences of forest fires in a Mediterranean landscape, Mt. Carmel Israel. Catena, 71, pp. 76-83. 